\title{
University, e-portfolio and students: perpetuating a sense of failure?
}

\author{
Helen Bardy, Lorraine Loveland-Armour, Sarah Parkes \\ Newman University Birmingham
}

\begin{abstract}
Newman University embraces partnership work according to the principles of a pedagogy of partnership, evidenced through development of Student Academic Partnership, Student Research Partnership and Student Community Partnership projects.

Driving enhancement of digital literacy in its graduates, the Youth and Community Work programme embraced the open source e-portfolio platform Mahara for use on study skills and placement modules. Staff, however, became aware of the difficulties encountered by students using Mahara and embarked on an initial 'Student Academic Partnership' project to unmask these and inform teaching development. This was subsequently followed by a 'Student Research Partnership' project that investigated specific difficulties for students with dyslexia.

The projects found that students valued peer-to-peer support rather than online support resources, and uncovered a variety of navigational issues that reinforces a sense of failure (Nosek, 1997), hindering progress and ultimately limiting opportunities for students creatively to express knowledge and understanding of a given subject.
\end{abstract}

\section{Newman University and Student Formation}

Newman University is a Catholic university and, as noted in the 2016/17 Access Agreement (p. 1), continues to exceed benchmarks for recruiting students from under-represented groups. The University directs research towards a demonstrable impact on society, whilst making Higher Education accessible to members of minority groups customarily deprived of it, and aims to achieve this through promoting student formation, defined as:

education for a reflective mind, for well-being and for human flourishing;

o within a community of intellectual enquiry, which is

- dedicated to the construction of the common good, the transformation of its members' lives and of the world they serve and engage with.

(Newman University, 2014, p. 3).

One of the ways in which student formation is embraced is through the notion of a pedagogy of partnership (Newman University, 2016) that draws from Catholic social teaching and emphasises Paulo Freire's idea of learning through critical co-investigation, where student and tutor are 'jointly responsible for a process in which all grow' (Freire,1996 p. 61). Newman's philosophy therefore seeks to build on his idea that leaders or teachers should not seek to speak to or for people but with them; furthermore, it promotes democratic engagement and co-operative working. This philosophy has more recently found favour with 
the National Union of Students (NUS), as a critical response to the marketisation of higher education. Its Manifesto for Partnership (NUS, 2015) rejects both the market and apprenticeship models of Higher Education in favour of a model of partnership where students are neither customers of Higher Education nor passive recipients of it. Instead, they are active partners in the life and learning of the University and partnership in this sense is the goal of student engagement. Alongside the NUS, the Quality Assurance Agency (QAA) has embraced the concept of partnership in its element of the Quality Code on student engagement, stating that 'Partnership working is based on the values of: openness; trust and honesty; agreed shared goals and values; and regular communication between the partners' (QAA, 2012, p. 5).

Influenced by Freire, the NUS and the QAA, Newman University thus characterises the pedagogy of partnership as:

- $\quad$ building from a shared hope [How can we improve our understanding and action?];

- $\quad$ establishing a dream of transformation [What is the best we can be?];

- $\quad$ promoting respectful dialogue [hearing under-represented voices] about our lived experience and espoused values;

- involving co-investigation and shared reflection through problem-posing, curiosity, rational exploration and creativity;

- $\quad$ seeking the co-construction of solutions aimed at a better way of being;

- $\quad$ an ongoing, transformative and collaborative process of being and becoming.

(Newman, University, 2016)

Evidence of this philosophy can be seen in the development over the last three years of Student Academic Partnership, Student Research Partnership and Student Community Partnership projects at the University. These wide-ranging projects have enabled staff to work with students to further their own understanding of student experience and thereby to enhance their teaching practice.

\section{Promoting digital literacy in Youth and Community Work}

For many years now, a fundamental element of all undergraduate degree programmes at Newman University has been a compulsory accredited work placement, either integrated in blocks throughout each level of study or completed as a specific module at level five. Historically, the traditional (and often lengthy) paper-based portfolio assessment was used; however, this was replaced on a select number of programmes with the open source eportfolio platform, Mahara. There has more recently been an institutional drive towards utilising Mahara on all work placement elements across the institution. This was seen as affording student flexibility and creativity through promoting use of a diverse range of media in assessment, rather than the traditional written form, potentially to bridge the 'digital divide' throughout the curriculum.

With the aim of improving the varying levels of digital literacy of students, Mahara was piloted in 2013/4 within the Youth and Community Work programme and across study skills and work placement modules at levels four and five. Here, students were asked to compile evidence from study skills development activities and their work placements across the year(s). One of the benefits of Mahara is that a 'secret URL' can be shared with others, 
allowing them to access student-selected and built resources contained within a specific page. This was envisaged as providing the opportunity for students to develop a digital CV in order to enhance their postgraduate employment prospects; it remains especially pertinent for Youth and Community Work students who need to be 'reflexive' practitioners. Part of all the modules utilising Mahara requires students to reflect on themselves continuously as they develop over the programme and during placement experiences. They thus can provide evidence for supervisors and potential employers of how they have been able to both 'reflect-in- action', and 'reflect-on-action' (Schön, 1983). This is achieved by including these reflections within a digital CV that utilises the 'secret URL'.

As this was an accredited Youth and Community Work programme, it was necessary to consider the needs of the accrediting body (National Youth Agency), by ensuring conformity to the benchmarks of both National Occupational Standards (NOS) and Quality Assurance Agency (QAA), as well as the needs of employers. Research by Davies and Cranston (2008), funded by the NYA (UK), found that, whilst Youth Work can play an important role in supporting young people to navigate the risks and exploit the opportunities available to them through social media and digital technologies, the professionals working with them might not have access to the technology themselves, nor the skills or knowledge base to perform this important informal educational role. Ensuring that Youth and Community Work graduates are digitally versatile therefore underpins the drive to make use of Mahara within the programme.

Despite using Mahara to increase flexibility and creativity, staff became more aware of the possible perpetuation of a digital divide caused by the digitisation of learning in Higher Education: the marginalisation of those with limited access to ICT for linguistic, social, educational, economic or geographical reasons (Selwyn and Facer, 2007). Indeed, following the first semester pilot in $2013 / 14$, it was noted that students with dyslexia in particular, some $50 \%$ of the programme's cohort, struggled to access and use Mahara effectively. Research maintains that students with dyslexia derive particular benefit from the use of assistive technology, because it can help with organisational difficulties, improve access to text and facilitate engagement with curriculum (Mortimore and Crozier, 2006, p. 246; Phayer, 2010, p. 29; Eide and Eide, 2011, p.182; Gregg and Banerjee, 2009, p. 271). However, studies also argue that assistive technologies alone cannot overcome barriers to accessing, engaging with and organising information for higher education students with dyslexia, as such other barriers as expectations and training requirements may restrict levels of engagement (Hanafin et al, 2007, p. 441).

These difficulties may be exacerbated by a lack of confidence with new technologies or the requirement to engage with technology in a more integrative way, which can in turn have impact on academic performance and engagement (Pino and Mortari, 2014, p. 347). Furthermore, despite their recognisable reasoning strengths, information overload for university students with dyslexia may present them with significant challenge in differentiating and prioritising the information they learn (Bacon and Handley, 2014, p. 341) as a consequence of difficulties within the cognitive domain of working memory (Pickering, 2012, p.11; Pickering, 2005, p.139; Velluntino and Fletcher, 2005, p. 367). Thus, these underlying cognitive difficulties compound their ability to access and consistently engage with assessments based within an e-portfolio environment. However, Hughes et al (2010, p. 59) argue that institutional use of Mahara as an alternative assessment tool could be refined, 
through personalisation opportunities within the e-portfolio structure, as an addition to the more experiential and systematic interventions for university students accessing dyslexia support. Thus, it became apparent that teaching and support staff needed to understand the specific barriers for such students at Newman University, to enable their successful and continuing use of the technology.

\section{Using Critical Pedagogical and Andragogical approaches to learning}

The foundation of the teaching context within the Youth and Community Work team is a Critical Pedagogical approach, placing transformative learning and education at the centre of the students' experience (Brookfield, 2003). This is in part owing to the educational role that they themselves will take as practitioners during and beyond their time within Higher Education. As the programme is practically applied, assessments also need to be practical and embedded in the students' current and future work as Youth and Community Workers. Students draw on the notion of 'engaged pedagogy' which requires praxis: the integration of theory and practice (hooks, 1994; 2003).

Whilst there are various competency-based benchmarks as previously mentioned, National Occupational Standards (NOS) and Quality Assurance Agency (QAA) may, in part, provide some guidance on enabling students to develop into reflexive practitioners. Threshold concepts (Meyer and Land, 2005; 2006) are used to help students navigate from a basic, compartmentalised understanding to one that is 'foundational, coherent and integrative, 'permeating the acquisition of new knowledge and ideas' (Meyer and Land: 2006b). Using Mahara as an assessment tool supports students to be creative in how they demonstrate their theory and practice, so that they can align the professional competencies, threshold concepts and skills that Richardson's (2013) model of 'measuring the immeasurable' notes as harder to assess, yet more important for students in a networked world.

Despite prior educational barriers to learning, students opt in to Dyslexia Support at Newman University. These decisions are typically informed by students' relatively new identity of dyslexia and the desire to drive their learning forward. Approaches to facilitate higher learning are predicated upon an andragogical stance, which assumes that the students' impetus to pursue university studies is informed by:

- the view that students have decided they need to know more about a self-selected topic of study;

- the learner has established a concept of self; the ability to overcome prior educational experiences;

- a readiness to learn;

- a "life-centred" approach to progressing in response to educational engagement;

- individual motivational factors;

- recognition of individual strengths contributing to resilience and motivation.

(Knowles, 1990, pp.57-63; Hunter-Carsch and Herrington, 2001)

By recognising and developing known strengths, rather than reinforcing prior negative experiences, students with dyslexia at Newman are able to engage in independent learning. They determine their own objectives and evaluate their academic development effectively within a support context in order to build additional strategies to complement or tweak 
existing compensatory strategies (Wilson and Savery, 2012; Eide and Eide, 2012; Burns, Poikkeus and Mikko, 2013; Glazzard and Dale, 2013).

Thus, the use of the Student Academic Partnership and Student Research Partnership initiative fits with the ethos of the approaches outlined above.

\section{Students in Partnership: Implementation}

In semester two of 2013/14, a Student Academic Partnership project within Youth and Community Work commenced. This sought to investigate the barriers to using Mahara, with the intention of using the findings to underpin future developments. Subsequently, an institution-wide Student Research Partnership project built on the original Student Academic Partnership, but specifically focused on the barriers and needs of students with dyslexia.

The first Student Academic Partnership project focused on the generic experience of using Mahara for all students on the Youth and Community Work programme. Students who had initially found Mahara difficult to navigate and yet had come to value its use were approached to take part; one level five student was keenly interested and signed up to the partnership. They in turn recruited two further students, who created their own informal space in order to talk to other students and seek information about their concerns regarding use of Mahara. Initially, 'Whatsapp' was used to communicate questions the Youth and Community students had identified as an issue, and many students voiced their concerns in this way. Some students also took it upon themselves to provide one-to-one support to others who acknowledged that they would benefit from additional help.

Students reported that they were uncertain about where to access help when using Mahara, the position of the 'Help Page' being considered unhelpful and not the first place they sought assistance. Students also felt less confident in using support from the online forum and indicated a preference for peer-to-peer support. Interestingly, the student partners themselves became informal mentors to other students through tacit learning support. This created an awareness of the benefits extra support for students would bring. What became clear from the discussions between students was that those with dyslexia were reporting greater difficulty in using Mahara.

In response to this initial project, the e-learning department at Newman University minimised specific Mahara features which students found problematic and streamlined the Help section so that it was more user-friendly. In addition, the approach to teaching and supporting Mahara use was adjusted to include more practice time in seminars and scheduled drop-in sessions, and student mentors were recruited to support students using Mahara for the first time.

Following the initial Student Academic Partnership, a Student Research Partnership project emerged that sought to investigate the particular barriers to using Mahara for students with dyslexia. This involved a variety of staff working together with a student with dyslexia. The student worked in partnership on a weekly basis with a specialist dyslexia support tutor to reflect on, evaluate and engage with Mahara. This approach ensured consistency, space and time for reflection / evaluation and cooperative planning, by actively using Mahara together in order to discuss and identify barriers: these revealed challenges not only with the technology, but also with following what were perceived as complicated sequences in order 
to adapt the portfolio. Indeed, recalling sequential information, organising and prioritising it in order to engage with it frequently constitute a challenge that characterises dyslexia (Eide and Eide, 2012; Berninger, et al, 2006; BDA, 2011; Shah and Miyake, 1996; Cornoldi, De Beni and Pazzaglia, 1996). Once key difficulties were identified, a concept map outlining how to navigate and create pages within Mahara was created. The concept map acted as a visual aid to stimulate narratives within semi-structured interviews conducted with six university students with dyslexia.

\section{Emerging themes}

Themes emerging from the project suggest that a core barrier to using Mahara effectively is rooted in the inconsistencies in sequential memory of participants identified with dyslexia, with significant impact on navigation. This can be identified across the different levels of study as seen below:

...Its overly complex and it doesn't need to be! It's got loads of different links on there

...if you're not sure of where you are looking... you looking in all the wrong places....

(Female student, Level Four)

...just dumb it down a bit better...it shouldn't have to be that you have to upload more

...it gets confusing....

(Male student, Level Six)

...it's a bit confusing.....where've your files actually gone?

(Female student, Level Five)

This challenge further impacts significantly on critical engagement with the Mahara tools, as each one requires the learner to engage with a series of additional steps.

The benefits of assistive technology for students with dyslexia is well documented (Mortimore and Crozier, 2006; Phayer, 2010; Eide and Eide, 2011; Gregg and Banerjee, 2009). However, in terms of Mahara, the systems for adding new features are not consistently mapped against more familiar and more frequently used software, which causes significant accessibility issues for participants. This can be seen in the exchange between a participant and the student interviewer:

Participant: One of the additional reasons I haven't used it...I don't know how to use it fully for me to be able to see how my assignment is progressing. I need to do it in a Word document.... Interviewer: ...something you're already familiar with? Participant: Yes

(Female Student, Level Six)

The teaching staff initially perceived that Mahara would enable students with dyslexia to make the most of their strengths by uploading visual and audio academic work. In addition, 
within dyslexia support, students have learnt to use dictaphones to record auditory reflections and other academic work. It was anticipated that this would be used as an alternative way of demonstrating knowledge. However, there was an additional challenge in this:

...we've got a certain amount of storage and pictures work for me but [they] take up a lot of data space! And if you're uploading visuals ... into your memory and data space as dyslexic students, we could possibly do with more memory?

(Female student, Level Five)

Therefore, because students with dyslexia typically have strengths in visual processing, they welcome the opportunity to present their ideas in a visual way. Indeed, overcoming the auditory working memory difficulty is also supported by the use of a dictaphone to record their thoughts as they have them, thus removing the barrier of having to type thoughts out. So it is that limitations of data storage and methods of mitigating these by compressing files add a further barrier to Mahara use.

As noted previously, university students with dyslexia can suffer information overload despite recognisable reasoning strengths. The quoted comment below reflects the initial confusion of students with dyslexia when using Mahara and demonstrates the determination, reasoning strengths and resilience used as coping strategies to manage the barriers:

\section{...Its very complicated. If you don't know where you are going or what you're doing! It was \\ only through trial and error that I was actually able to achieve what I wanted to achieve from Mahara. If I wasn't as curious as I am then I probably wouldn't have been able to produce what I did on Mahara....}

(Female student, Level Four)

These underlying cognitive difficulties compound the ability to access and consistently engage with assessments that are based within an e-portfolio environment. Consequently, the features within the Mahara menu, although many and varied in terms of allowing students to present their understanding through a variety of formats, require the recoding of icons and labels. This recoding proves to be highly inconsistent for students with dyslexia, contributing to self-doubt and disengagement with the e-portfolio. Therefore, for them, the potential creative opportunities to demonstrate knowledge and understanding are superseded by incompatible labelling, the structural make-up of the pages and the twodimensional nature of the portfolio.

\section{Navigation, Navigation, Navigation.}

Each session within Mahara means starting the navigation process afresh in order to find the pages and the items within the pages within individual e-portfolios. This seems to lead to replication and repetition of ideas in multiple pages, with significant ensuing impact on editing requirements. Students often suggested that they should write out steps or create maps in order to navigate to previously-uploaded materials. Furthermore, the additional time investment required to begin each page for each portfolio means that students have to reacquaint themselves with the previously imposed structure of pages before creating new 
ones in order to remind themselves of their progress. Whilst there are known benefits to overlearning for students with dyslexia (Reid, 2016; Price, 2013, p. 57), the learning opportunities in engaging with the portfolio in this manner are minimal as the starting point doesn't build further knowledge, but does, for these students, reinforce a sense of failure (Nosek, 1997) that hinders progress and limits opportunities to express creatively knowledge and understanding of a given subject. However, it must also be noted that through this process of using, discussing and reflecting on how to access and engage with Mahara, students are finding that they are developing more strategies to manage navigation. Dialogic talk supports students involved in this study to bypass some of the impact resulting from working memory inconsistencies and appears to be suggesting that resilience ultimately is driven by the struggle and the opportunity to discuss the nature of the struggle with a learning partner. Moreover, a constructive, problem-solving approach to engagement with Mahara has also, in the form of recommendations for colleagues across the institution, initiated suggestions for how to improve the portfolio structure in order to reduce barriers to learning.

\section{Evaluation and limitations}

A potential limitation of this study is that students without dyslexia were not involved. As a result, it is impossible to know whether or not these user experiences are disparate from neurotypical students using Mahara as an assessment tool. Nonetheless, these initial findings are contrary to the easy fit with an e-portfolio as an assessment tool which also facilitated independent learning opportunities expressed in Hughes et al, (2011, p. 59). A number of factors may contribute to this, particularly the approaches to dialogic engagement when using the e-portfolio through forums. Furthermore, in line with Williams et al, (2014, p. 622), despite the difficulties that students in this study encountered, e-portfolios as an assessment tool must not be discounted: They offer valuable means of alternative assessment for students with dyslexia because there is potential to embed a more inclusive, personalised and dialogic means of critical engagement with their subject areas. This notion is complementary to emerging themes, which suggest that there are staff development and andragogical considerations that need to be addressed in order to maximise the potential benefits of using Mahara as an assessment tool for university students with dyslexia.

\section{Recommendations and outputs}

Following on from completion of the Student Research Partnership project (15/16), developments at Newman University have included:

1. construction of an institutional Mahara Working group to discuss the challenges, with a view to overcoming barriers to its use;

2. internal investigations by the e-learning team at Newman into any adaptations to the software that can be made in-house;

3. dissemination of the findings and those adaptations that require external implementation shared with the software publisher as requested - a response to the initial Student Academic Partnership (13/14) project.

4. creation of two internal resources: 
a. a visual resource to support use of Mahara is in production, with a view to adding this to the home page of Mahara as a learning and teaching resource for both staff and students.

b. a Mahara collection of resources produced collaboratively during the course of the research project.

In agreement with Hughes, et al (2010), how Newman University further develops its use of Mahara as an alternative assessment tool may be potentially refined through personalisation opportunities within the e-portfolio structure, alongside more experiential and systematic interventions for university students accessing dyslexia support.

\section{Reference List}

Bacon, A.M. and Handley, S.J. (2014) 'Reasoning and dyslexia: is visual memory a compensatory resource?' Dyslexia, 20(4), 330-345.

BDA (2011) Dyslexia and SpLD in adults. Bracknell: British Dyslexia Association Brookfield.

Berninger, V.W., Abbott, R.D., Thomson, J., Wagner, R., Swanson, H.L., Wijsman, E.M. and Raskind, W. (2006) 'Modeling phonological core deficits within a working memory architecture in children and adults with developmental dyslexia.' Scientific Studies of Reading. 10 (2), 165-198.

Brookfield, S. (2003) 'A critical theory perspective on accelerated learning'. New Directions for Adults and Continuing Education, 97, 73-82. Available at:

http://onlinelibrary.wiley.com/doi/10.1002/ace.90/epdf (Accessed: 19 November 2015). DOI: 10.10.02/ace.90

Burns, E., Poikkeus, A-M. and Mikko, A. (2013) 'Resilience strategies employed by teachers with dyslexia working at tertiary education.' Teaching \& Teacher Education, 34, 77-85.

Cornold, C., De Beni, R. and Pazzaglia, F. (1996) 'Profiles of reading comprehension difficulties: an analysis of single cases.' In: Reading comprehension difficulties: processes and interventions. Cornoldi, C. and Oakhill, J. (eds.), 113-136. Mahwah, NJ: LEA.

Davies, T. and Cranston, P. (2008) Youth Work and Social Networking Final Research Report: How can Youth Work best support young people to navigate the risks and make the most of the opportunities of online social networking? Leicester: National Youth Agency.

Eide, B. L. and Eide, F.F. (2011) The dyslexic advantage. London: Hay House.

Freire, P. (1996) Pedagogy of the Oppressed, $2^{\text {nd }}$ Ed. London: Penguin Books.

Glazzard, J. and Dale, K. (2013) 'Trainee teachers with dyslexia: personal narratives of resilience.' Journal of Research in Special Educational Needs, 13 (1), 26-37.

Gregg, N. and Banerjee, M. (2009) 'Reading comprehension solutions for college students with dyslexia in an era of technology: an integrated approach.' In: Reid, G. (ed.), The Routledge companion to dyslexia, 265-285. Abingdon: Routledge. 
Hooks, B. (1994) Teaching to Transgress. Education as the practice of freedom. London: Routledge.

Hooks, B. (2003) Teaching Community. A pedagogy of hope. New York: Routledge.

Hughes, J., Herrington, M. McDonald, T. and Rhodes, A. (2010) ‘E-portfolios and personalized learning: research in practice with two dyslexic learners in UK higher education.' Dyslexia, 17, 48-64. Available at:

http://onlinelibrary.wiley.com/doi/10.1002/dys.418/abstract (Accessed: 12 December 2014). DOI: $10.1002 /$ dys.418.

Hunter-Carsch, M. and Herrington, M. (2001) Dyslexia and effective learning in secondary and tertiary education, London: Whurr Publishers.

Knowles, M. (1990) The adult learner a neglected species, 4th Edn. Houston, TX: Gulf Publishing Company.

Meyer, J.H.F. and Land, R. (2005) 'Threshold concepts and troublesome knowledge (2): epistemological considerations and a conceptual framework for teaching and learning.' Higher Education, 49 (3), pp.373-388.

Meyer, J.H.F., Land, R. and Davies, P. (2006) 'Implications of threshold concepts for course design and evaluation.' In: Meyer, J.H.F. and Land, R. (eds.), Overcoming Barriers to Student Understanding: threshold concepts and troublesome knowledge. London: Routledge.

Mortimore, T. and Crozier, W.R. (2006) 'Dyslexia and difficulties with study skills in higher education.' Studies in Higher Education. 31(2), 235-251.

Newman University, (2014) Strategic Plan 2014-2020. Available at: http://www.newman.ac.uk/files/w3/about-us/pdf/Strategic\%20Plan\%2020142020\%20.pdf?q=277 (Accessed: 17 March 2016).

Newman University (2016) Pedagogy of Partnership. Available at: http://www.newman.ac.uk/about-us/3931/the-pedagogy-of-partnership (Accessed: 08 April 2016).

Newman University (2016b) Enhancing retention, progression and achievement through student partnership. [Internal document]

Nosek, K. (1997) Dyslexia in adults: taking charge of your life. Lanham, MD: Taylor Trade Publishing.

National Union of Students (2015) A Manifesto for Partnership. Available at: http://www.nusconnect.org.uk/resources/a-manifesto-for-partnership (Accessed: 15 January 2016).

Pickering, S.J. (2012) 'Working memory in dyslexia.' In: Packiam, T. and Gathercole, S.E. (eds.), Working memory and neurodevelopmental disorders, 7-40. Hove: Psychology Press. 
Pickering, S.J. (2005) 'Verbal memory in the learning of literacy.' In: Turner, M. and Rack, J. (eds.), The study of dyslexia, 131-156. Dordrecht, Netherlands: Springer Science + Business Media, Inc.

Pino, M. and Mortari, L. (2014) 'The inclusion of students with dyslexia in higher education: a systematic review using narrative synthesis.' Dyslexia, 20, 346-369. Available at: https://www.ncbi.nlm.nih.gov/pmc/articles/PMC4253321/ (Accessed: 09 September 2015). DOI: 10.1002/dys.1484.

Price, G. (2012) 'Why can't I learn? metacognitive strategy instruction.' In: Brunswick, N. (ed.) Supporting Dyslexic Adults in Higher Education and the Workplace, 51-58. Oxford: John, Wiley \& Sons, Ltd.

Quality Assurance Agency (2012) UK Quality Code for Higher Education - Chapter B5: Student engagement. Available at: http://www.qaa.ac.uk/publications/information-andguidance/uk-quality-code-for-higher-education-chapter-b5-student-engagement\#.VyM6vkrLIU (Accessed 20 February 2013).

Reid, G. (2016) Dyslexia: a practitioner's handbook. 5th Edn. Chichester: John Wiley \& Sons Ltd.

Richardson, W. (2012) 'Messy Assessment.' The "Immeasurable” part 2, 3 August. Available at: http://willrichardson.com/post/28626310240/the-immeasurable-part-2 (Accessed: 04 April 2015).

Schön, D. (1983) The Reflective Practitioner: How Professionals Think in Action. USA: Basic Books.

Selwyn, N. and Facer, K. (2007) Beyond the digital divide: Rethinking digital inclusion for the 21st century. Available at:

http://archive.futurelab.org.uk/resources/documents/opening education/Digital Divide.pdf (Accessed: 05 May 2009).

Shah, P. and Miyake, A. (1996) 'The separability of working memory resources for spatial thinking and language processing: an individual differences approach.' Journal of Experimental Psychology: General, 125, 4-27.

Velluntino, F. and Fletcher, J.M. (2005) 'Developmental dyslexia.' In: Snowling, M.J. and Hulme, C. (eds.), The science of reading: a handbook, 362-378. Oxford: Blackwell Publishing.

Williams, P., Wray, J., Farrall, H. and Aspland, J. (2014) 'Fit for purpose: traditional assessment is failing undergraduates with learning difficulties. Might e-assessment help?' International Journal of Inclusive Education, 18 (6), 614-625.

Wilson, M. and Savery, N. (2012) 'Stories of resilience: Learning from adult students' experiences of studying with dyslexia in tertiary education.' Journal of Adult Learning, Aotearoa New Zealand, 40 (1), 110-126. 